\title{
Perspectiva de la familia / cuidador sobre el dolor crónico en pacientes con cuidados paliativos 1
}

\author{
Rudval Souza da Silva ${ }^{2}$, Eliã da Silva Araújo Oliveira ${ }^{3}$, Jeany Freire de Oliveira ${ }^{4}$, Maria Olivia Sobral Fraga \\ Medeiros $^{5}$, Mariana do Valle Meira ${ }^{6}$, Christielle Lidianne Alencar Marinho ${ }^{7}$
}

Institución: Universidad Federal de Bahía

\section{RESUMEN}

El objetivo de esta investigación fue conocer la perspectiva del familiar / cuidador en el enfrentamiento del dolor crónico de su ser querido en cuidados paliativos. Para la recolección de datos, se aplicó la entrevista semiestructurada y fue realizada en los meses de enero a abril de 2018 con nueve familiares / cuidadores de pacientes en cuidados paliativos con dolor crónico. Para el análisis, se utilizó la Técnica de Análisis de Contenido de Bardin y los resultados discutidos sobre la base de la literatura relacionada. Del análisis surgieron cuatro categorías: 1) Sentimientos vivenciados por familiares / cuidadores; 2) Uso limitado de analgésicos como recurso terapéutico para control álgico; 3) Desconocimiento de las terapias no farmacológicas en el manejo de las crisis álgicas y, 4) La comunicación como recurso terapéutico de soporte en las crisis álgicas. Se concluye que el dolor todavía no es bien tratado y ese hecho contribuye al aumento del sufrimiento tanto del paciente y del familiar/cuidador.

Palabras claves: Cuidadores; Cuidados-paliativos; Dolor-crónico; Enfermería; Familia.

DOI 10.15517/revenf.v0i38.37086

${ }^{1}$ Fecha de recepción: 30 de abril del 2019

Fecha de aceptación: 23 de setiembre del 2019

${ }^{2}$ Enfermero. Doctor en Enfermería. Universidad Federal de Bahía UFBA. Profesor Adjunto - UNEB/Campus VII- Señor de Bonfim Correo electrónico: rudvalsouza@yahoo.com.br

${ }^{3}$ Enfermera. Universidad del Estado de Bahía - UNEB/Campus VII. Señor de Bonfim, Ba, Brasil. Correo electrónico: elia10.oliveira@gmail.com

${ }^{4}$ Enfermera. Máster en Ciencias de la Salud y Biológicas. Universidad Federal del Valle de San Francisco (UNIVASF). Señor de Bonfim, Ba, Brasil. Correo electrónico: jeanyfroliver@hotmail.com

${ }^{5}$ Enfermera. Máster en Enfermería y Salud. Universidad Federal de Bahía (UFBA). Salvador, Ba, Brasil. Correo electrónico: poppmedeiros@yahoo.com.br

${ }^{6}$ Enfermera. Hospital General del Salvador. Salvador, Ba, Brasil. Correo electrónico: mariana.meira12@gmail.com

${ }^{7}$ Enfermera. Doctoranda en Ciencias de Salud. Universidad de Pernambuco. Docente en UNEB/Campus VII - Señor de Bonfim. Correo electrónico: christiellealencar@yahoo.com.br 


\title{
Family / caregiver's perspective on chronic pain in palliative care patients ${ }^{1}$
}

\author{
Rudval Souza da Silva ${ }^{2}$, Eliã da Silva Araújo Oliveira ${ }^{3}$, Jeany Freire de Oliveira ${ }^{4}$, Maria Olivia Sobral Fraga \\ Medeiros $^{5}$, Mariana do Valle Meira ${ }^{6}$, Christielle Lidianne Alencar Marinho ${ }^{7}$
}

Institution: Bahia State University

\begin{abstract}
The aim of this research was to know the perspective of the family/caregiver in facing the chronic pain of their loved one in palliative care. Data collection used the semi-structured interview and was performed in the months of January to April of 2018 with nine family/caregiver of patients in palliative care with chronic pain. For analysis, the Bardin Content Analysis Technique was used, and the results discussed based on the related literature. Four categories emerged from the analysis: 1) Feelings experienced by family/caregiver; 2) Limited use of analgesics as a therapeutic resource for pain control; 3) Lack of knowledge of non-pharmacological therapies in pain management; and 4) Communication as a therapeutic resource for pain relief. It is concluded that the pain is still underused, and this fact contributes to the increase of the suffering of the patient as well as the family/caregiver.
\end{abstract}

Keywords: Caregivers; Chronical-suffering; Family; Nursing; Palliative Cares.

DOI 10.15517/revenf.v0i38.37086

${ }^{1}$ Date of receip: April 30, 2019

${ }^{2}$ Nurse. PhD in Nursing. Federal University of Bahia UFBA. Adjunct Professor - UNEB/ Campus VII. Lord of Bonfim, Ba, Brazil. Email: rudvalsouza@yahoo.com.br

${ }^{3}$ Nurse. State University of Bahia - UNEB / Campus VII. Lord of Bonfim, Ba, Brazil. E-mail: elia10.oliveira@gmail.com

${ }^{4}$ Nurse. Master in Health and Biological Sciences, Federal University of Vale do São Francisco (UNIVASF). Lord of Bonfim, Ba, Brazil. E-mail: jeanyfroliver@hotmail.com

${ }^{5}$ Nurse. Master in Nursing and Health at the Federal University of Bahia (UFBA). Salvador, Ba, Brazil. E-mail: poppmedeiros@yahoo.com.br

${ }^{6}$ Nurse. Salvador General Hospital. Salvador, Ba, Brazil. E-mail: mariana.meira12@gmail.com

${ }^{7}$ Nurse. PhD in Health Sciences. University of Pernambuco. Teacher at UNEB / Campus VII - Lord of Bonfim. E-mail:

christiellealencar@yahoo.com.br 


\title{
Perspectiva do familiar/cuidador sobre a dor crônica no paciente em cuidados paliativos ${ }^{1}$
}

\author{
Rudval Souza da Silva ${ }^{2}$, Eliã da Silva Araújo Oliveira ${ }^{3}$, Jeany Freire de Oliveira ${ }^{4}$, Maria Olivia Sobral Fraga \\ Medeiros $^{5}$, Mariana do Valle Meira ${ }^{6}$, Christielle Lidianne Alencar Marinho ${ }^{7}$
}

Instituição: Universidade do Estado da Bahia

\section{RESUMO}

O objetivo desta investigação foi conhecer a perspectiva do familiar/cuidador no enfrentamento da dor crônica do seu ente querido em cuidados paliativos. A coleta de dados utilizou a entrevista semiestruturada e foi realizada nos meses de janeiro a abril de 2018 com nove familiares/cuidadores de pacientes em cuidados paliativos com dor crônica. Para análise, foi utilizada a Técnica de Análise de Conteúdo de Bardin e os resultados discutidos com base na literatura correlata. Da análise emergiram quatro categorias: 1) Sentimentos vivenciados por familiares/cuidadores; 2) Uso limitado de analgésicos como recurso terapêutico para controle álgico; 3) Desconhecimento das terapias não farmacológicas no manejo das crises álgicas e 4) A comunicação como recurso terapêutico de suporte nas crises álgicas. Conclui-se que a dor ainda é subtratada e esse fato contribui para o aumento do sofrimento tanto do paciente quanto do familiar/cuidador.

Palavras-chaves: Cuidadores; Cuidados Paliativos; Dor crônica; Enfermagem; Família.

DOI 10.15517/revenf.v0i38.37086

${ }^{1}$ Data da recepção 30 de abril de 2019

Data da aceitação: 23 de setembro de 2019

${ }^{2}$ Enfermeiro. Doutor em Enfermagem. Universidade Federal do Estado da Bahia UFBA. Professor Adjunto - UNEB. Correio eletrônico: rudvalsouza@yahoo.com.br

${ }^{3}$ Enfermeira. Universidade do Estado da Bahia - UNEB/Campus VII. Senhor do Bonfim, Ba, Brasil. Correio eletrônico: elia10.oliveira@gmail.com

${ }^{4}$ Enfermeira. Mestranda em Ciências da Saúde e Biológicas. Universidade Federal do Vale do São Francisco (UNIVASF). Senhor do Bonfim, Ba, Brasil. Correio eletrônico: jeanyfroliver@hotmail.com

${ }^{5}$ Enfermeira. Mestranda em Enfermagem e Saúde. Universidade Federal da Bahia (UFBA). Salvador, Ba, Brasil. Correio eletrônico: poppmedeiros@yahoo.com.br

${ }^{6}$ Enfermeira. Hospital Geral de Salvador. Salvador, Ba, Brasil. Correio eletrônico: mariana.meira12@gmail.com

${ }^{7}$ Enfermeira. Doctoranda en Ciencias de Salud. Universidad de Pernambuco. Docente na UNEB/Campus VII - Señor de Bonfim.

Correio eletrônico: christiellealencar@yahoo.com.br 


\section{INTRODUÇÃO}

A morte está presente no cotidiano das vivências coletivas e na formação dos trabalhadores da saúde, porém ainda é uma temática que é tratada de forma técnica e carregada de tabus nos distintos espaços de assistência a saúde ${ }^{1}$. Apesar da morte ser um fenômeno parte do processo natural da vida e uma ocorrência constante no cotidiano dos profissionais de saúde, estes ainda a veem como uma inimiga a ser vencida, ou quando não conseguem vencê-la, sentem-se na condição de derrotados.

Percebe-se que de fato a morte é tida como um acontecimento atemorizante, condição esta que precisa ser desconstruída e, para tanto os conhecimentos sobre Tanatologia e os Cuidados Paliativos podem ser o início deste diálogo.

Tais abordagens são de fundamental importância diante do arcabouço de saberes que visam proporcionar ao paciente e sua família, reflexões e atitudes de resiliência de modo a ajudar a melhor convivência com a situação de adoecimento do ente querido e a proporcionar dignidade no processo de morrer e na morte. Os princípios norteadores dos cuidados paliativos têm como foco principal a qualidade de vida e a dignidade humana ${ }^{2}$.

Historicamente os Cuidados Paliativos têm tido um impacto social positivo com repercussão na saúde das pessoas em processo de morrer $^{1-2}$. O movimento moderno pelos cuidados paliativos teve início a partir dos esforços de uma grande personalidade, a enfermeira, assistente social e médica inglesa Cicely Saunders, a idealizadora e criadora, na década de 1960, do St. Christopher Hospice na cidade de Londres no Reino Unido. Sendo este um fato marcante no modo de assistir a pessoa que está morrendo, de forma integral, com respeito a sua autonomia e a dignidade humana ${ }^{3}$.

Para cuidar com foco na abordagem dos cuidados paliativos, faz-se necessário uma atuação em equipe interdisciplinar, com formação especializada com ênfase numa comunicação compassiva, atenção à família e conhecimento no manejo de sintomas ${ }^{2}$. Nesse contexto, a enfermeira tem um papel relevante na composição da equipe, de modo a atuar juntamente com o médico e demais profissionais da equipe multidisciplinar ${ }^{4}$.

O cuidado com a família é parte essencial desse processo, a qual integra a unidade de cuidados - paciente/família e deve ser vista e assistida pela equipe de cuidados paliativos, fortalecendo os vínculos entre família, paciente e equipe, em busca por alcançar um resultado satisfatório nessa fase tão difícil que é o processo de morrer ${ }^{5}$. Para tal, a comunicação é o pilar dessa convivência e, em prol de um patamar eficiente e eficaz é preciso estabelecer um diálogo aberto, de confiança mútua e verdadeira, de modo que o plano terapêutico seja construído e acordado entre paciente, família e equipe. Dentre os instrumentos de comunicação, pode ser citada a conferência familiar como uma das formas de abordagem terapêutica que oportuniza o tripé: paciente, família e equipe a desenvolver uma comunicação afetiva e efetiva ${ }^{6}$.

Para além dos cuidados com a família, o trabalho em equipe baseado numa comunicação compassiva, é imprescindível e deve buscar uma atenção especial no controle dos sintomas no paciente em cuidados paliativos, em especial a dor crônica, a qual por si só, já compromete a qualidade de vida dos pacientes com doenças terminais. Assim, é necessário que haja um monitoramento eficaz para controlar e diminuir esse efeito, tornando sua prevenção um meio viável para que o sofrimento possa ser aliviado ${ }^{7}$. 
Pressupõe-se que conhecer como a família percebe o cuidado com a dor crônica, pode proporcionar oportunidade de reflexões por parte da equipe sobre mudanças de paradigmas na assistência à pessoa em cuidados paliativos, com ênfase no melhor manejo da dor e no alívio do sofrimento. Nessa perspectiva, surgem as seguintes perguntas de investigação: Qual a perspectiva da família diante do controle da dor crônica em seu ente querido em cuidados paliativos? E, quais as estratégias utilizadas pelo familiar/cuidador no lidar com a dor crônica de seu ente querido? Assim, o presente artigo tem como objetivo conhecer a perspectiva do familiar/cuidador no enfrentamento da dor crônica do seu ente querido em cuidados paliativos.

\section{METODOLOGIA}

Trata-se de um estudo exploratório e descritivo, de abordagem qualitativa, que buscou analisar os dados levantados por meio de entrevistas semiestruturadas com familiares cuidadores de pacientes em cuidados paliativos e com relato de dor crônica, na região do Piemonte da Chapada Diamantina no Norte do Itapicuru, Bahia, Brasil. A aproximação com os participantes do estudo ocorreu por meio da Técnica da Bola de Neve, a qual busca identificar participantes a partir de redes de convivências/sociais como forma de obter sua população de estudo. A indicação vem de uma pessoa chave que deu a recomendação de uma fonte de informação e fez a primeira intermediação entre pesquisador e participante ampliando assim o leque de participantes do estudo ${ }^{8}$.

Foram adotados como critérios de inclusão: ser familiar/cuidador de pessoa com doença oncológica, relato de dor crônica e ser maior de dezoito anos. E como critérios de exclusão: ausência de queixa de dor crônica e o cuidador principal não ser um familiar. Todos os participantes foram esclarecidos e após o aceite em participar da pesquisa, assinaram o Termo de Consentimento Livre Esclarecido (TCLE).

As entrevistas ocorreram em local reservado, em data e hora previamente agendadas, nos meses de janeiro a abril de 2018, foram audiogravadas e em seguida transcritas para posterior análise, a qual ocorreu com base na Técnica de Análise de Conteúdo de Bardin 9 . A coleta dos dados foi encerrada no momento em que foi identificado os sinais de saturação, ou seja, ponto no qual não se obtinha nenhuma nova informação sobre o fenômeno em estudo. A análise dos dados seguiu o fluxo metodológico conforme recomenda a Técnica de Análise de Conteúdo $\left.{ }^{9}: 1\right)$ pré-análise - realizada por meio da leitura exaustiva das falas em busca de melhor conhecer, compreender e interpretar o conteúdo nelas impressos; 2) exploração do material - etapa em que ocorreram os recortes das entrevistas, o que originou as unidades de registro e em seguida as unidades de significado; 3 ) tratamento dos resultados - como etapa final de análise, possibilitou emergir as categorias de maior relevância em relação ao objeto de estudo, as quais posteriormente foram discutidas de acordo com a literatura correlata.

Da análise, emergiram quatro categorias temáticas: 1) Sentimentos vivenciados por familiares/cuidadores; 2) Uso limitado de analgésicos como recurso terapêutico para controle álgico; 3) Desconhecimento das terapias não farmacológicas no manejo das crises álgicas e, 4) A comunicação como recurso terapêutico de suporte nas crises álgicas.

\section{Considerações éticas}

O estudo foi apreciado e aprovado pelo Conselho de Ética e Pesquisa/UNEB sob o $\mathrm{n}^{\circ}$ 2.245.482/2017, sendo respeitados os preceitos éticos e legais concernentes às investigações com seres humanos, conforme preconizam 
as resoluções n 466 de 12 de dezembro de 2012 e n 510 de 07 de abril de 2016, do Conselho Nacional de Saúde ${ }^{9-}$ 10

\section{RESULTADOS}

\section{Caracterização dos familiares/cuidadores - participantes do estudo}

Dos nove participantes, sete eram mulheres e dois homens, com idade que variou entre 27 e 65 anos. Todos informaram ser o cuidador principal e familiar do paciente. Os pacientes apresentavam diagnóstico clínico de doença oncológica e histórico de dor crônica. Quanto ao tempo de prestação dos cuidados, este variou entre dois meses e cinco anos. Quanto à religião seis declararam o catolicismo; dois, o protestantismo e um, declarou-se sem religião. Sobre o nível de escolaridade, dois participantes informaram ter nível superior; quatro, com nível médio; dois, com ensino fundamental completo e um, não escolarizado.

\section{Categorias temáticas}

\section{Categoria 01: Sentimentos vivenciados por familiares cuidadores}

Devido à ação devastadora da doença, em especial a doença oncológica, que foi parte do cenário dos participantes deste estudo, foi possível inferir que os sentimentos de medo, medo da morte, do desconhecido, a angústia, insegurança e impotência, foram aqueles que mais marcaram as falas dos familiares/cuidadores em relação ao cuidado do seu ente querido com dor crônica. Como pode ser observado nos fragmentos de falas apresentados a seguir:

Bastante medo. O nome câncer traz junto uma sentença de morte. (F1)

Trouxe medo e angústia, hoje em dia quando alguém fala de que alguém faleceu que a gente sabe que tava com a doença, eu já associo logo a ele assim, você associa logo ao seu familiar. (F2)

Muito angustiante, eu senti muito pela família que chorou bastante, tinha medo que ela não conseguisse se recuperar (F5).

O sentimento que eu tive era que ela ia morrer, e foi um choque pra toda família, todo mundo mesmo, a doença por si só já agravava, todo mundo dizia vai morrer. (F7)

Meu sentimento é muita dor, dor profunda, medo de perder a irmã, medo de ver as crianças precisando dela [choro]. (F9)

\section{Categoria 02: Uso limitado de analgésicos como recurso terapêutico para controle álgico}

Seguir com rigorosidade a prescrição medicamentosa em relação aos analgésicos como principal forma de alívio da dor marcou as falas dos entrevistados, com a ressalva de que nenhum cita o uso da morfina no controle da dor, mesmo aqueles que relatam o não controle da dor com os analgésicos fracos, tendo como consequência um controle inadequado da dor crônica e o aumento do sofrimento devido ao seu subtratamento, como pode ser ilustrado com as seguintes falas: 
Eu converso com ela para ela tomar a medicação certa na hora certa e na dosagem. (F1)

Dou o medicamento na hora correta para evitar a dor, mas não recebi nenhuma orientação para aliviar a dor. Ele diz que já tá cansado, não aguenta mais isso. (F2)

Eu dou Dipirona quando ele tá gemendo [...] Dipirona, que é o que o médico passa [...]Tem vez que ele fica tão, agoniado tão nervoso [...] eu dei o remédio, mas não serviu de nada[...]Ele geme a noite toda, em todo lugar que ele se vira ele geme (F3).

Ela tem crises de dor fortíssima que infelizmente ou felizmente só alivia com o uso da Dolantina (F6).

A crise é quando movimentava ela, se ela ficasse deitada ela não sentia nada, mas se movimentasse para dá banho, ir no banheiro ai ela sentia dor quando movimentava ela (F8).

\section{Categoria 03: Desconhecimento das terapias não farmacológicas no manejo das crises álgicas}

Das falas analisadas não foi possível observar relato de uso das terapias não farmacológicas para o controle e alívio da dor crônica. As ideias das mensagens giram sempre em torno do uso dos analgésicos alopáticos. Nenhum dos participantes mencionou o uso das práticas integrativas e complementares. Os relatos transmitem a mensagem de que os familiares/cuidadores nunca ouviram falar das medidas não farmacológicas para alívio da dor, com exceção de uma participante que mesmo não tenho esta consciência, citou o uso de chás.

Eu só sei lidar com a dor assim tomar o remédio assim, tomar no tempo adequado, mas outra coisa eu não sei não. (F1)

Nunca ouvi falar nisso de prevenção de dor (F3).

Ai ela (paciente) me orienta eu quero um chá, de tal coisa aí eu vou lá e faço. [...] não nunca ouvi se eu falar em técnica de alívio de dor pra você eu tô mentido (F4).

Levantar ela, sempre segurando no local que estava afetado pressionar com força mesmo e ali ela não ia sentir a dor, então a gente tentava ter sempre esse cuidado [...] não tenho esse conhecimento nenhuma de técnica de alivio de dor (F9).

\section{Categoria 04: A comunicação como recurso terapêutico de suporte nas crises álgicas}

Os familiares descrevem em suas falas que sempre estão conversando com os seus entes queridos e procuram não os deixar sozinhos durante as crises de dor, assim permanecem com eles conversando, fazendo companhia para que se sintam assistidos em suas aflições. Por conseguinte, foi possível identificar o uso de estratégias como a comunicação compassiva e a presença marcante, citados como medidas de conforto que acalmam o paciente. Recursos que têm demostrado efeito benéfico, como pode ser observado nas falas a seguir:

Consigo falar com ela de como ela quer ser tratada ela faz os pedidos dela [...] Quando está na crise de dor tento acalmar segurando na mão (F1).

Conversar, ficar ouvindo[...] tentar deixar ele mais calmo para evitar ansiedade (F2).

Olha, eu pergunto pra ela "o que é melhor pra você? o que eu posso fazer pra você?" aí ela me orienta ela sempre tá comigo, eu nunca deixo ela só, ela pede pra mim isso. (F4) 


\section{A gente sempre procura conversar muito com ela (F6).}

A gente faz o possível e o impossível para não deixar ela só, a gente faz de tudo pra tá perto e ela tá bem e motivada (F7).

\section{DISCUSSÃO}

Vale destacar a questão de gênero quanto à prestação dos cuidados com o predomínio do feminino, como já esperado e identificado em outros estudos que mostram que tal condição é uma construção histórica da figura feminina, intrínseca as práticas do cuidar ${ }^{12}$.

Todavia, o que nos instiga a trazer essa discussão, foram as falas de dois familiares/cuidadores, homens, que evidenciam a fragilidade na prestação dos cuidados e talvez a ausência de uma sensibilidade autocontrolada para cuidar de um ente com uma doença terminal, no momento que eles relatam que não conseguem suportar o sofrimento do outro em uma crise de dor, tendo como reação a fuga ou o pedido de ajuda à mulher mais próxima que encontra.

Dentre os sentimentos apontados pelos entrevistados, o medo e a impotência foram os mais marcantes, o que é comum diante de situações de perdas. Estudos mostram que as crenças familiares e suas vivências de perda é o que determinará a forma de como essa família passa a agir frente ao diagnóstico de uma doença fora de possibilidade de cura em um ente querido ${ }^{12}$.

Os resultados apontam também um fato notório de que no enfretamento de uma doença terminal em um membro da família, esta sofre, pois recai sobre ela a presença das vivências com a finitude da vida. Logo, é necessário que sejam estabelecidas medidas de reorganização de suas vidas, com suporte da equipe a este familiar/cuidador.

Tal apoio deve ocorrer com base nos princípios filosóficos dos cuidados paliativos, abordagem filosófica que reconhece que o fim da vida precisa ser encarado da forma mais natural possível, onde a morte faz parte da etapa da vida e para aqueles que ficam, os familiares, é necessário haver um plano de cuidados, tão essencial quanto os cuidados prestados ao paciente.

Estudo realizado na Noruega com familiares de paciente em cuidados paliativos e que investigou o sofrimento destes familiares quando da prestação dos cuidados, aponta que o sofrimento familiar é um reflexo do sofrimento do doente, e isso traz para o cuidador uma desordem de sentimentos no acompanhamento de seu familiar, pois há uma identificação na relação angustiante, o que é sentido intensamente por ambos ${ }^{13}$. Nesse conflito de sentimentos os familiares vivenciam uma carga emocional muito pesada, por necessitar manter o equilíbrio para continuar prestando o cuidado ao seu ente querido mesmo diante da inexorabilidade da morte.

O medo da morte gera o sentimento de perda, de luto, o que se inicia desde o momento que a pessoa percebe que a morte é iminente, o que traz a necessidade de ajustamento à nova realidade que a condição apresenta, impactando as funções familiares e modificando-as, e no geral, diante desta situação associa-se outra que é a de que apenas um membro da família passa a ser o cuidador principal ${ }^{14}$, condição tal que acarreta uma sobrecarga sobre este familiar/cuidador. 
A sensação de que a morte está sempre rondando o cotidiano de quem cuida está presente nos discursos de todos os familiares participantes deste estudo. Pesquisas ${ }^{14-15}$ salientam que estes familiares mencionam que a sentença de morte está lançada sobre seu ente querido, o que leva a um sentimento antecipado de perda. É preciso que esse aspecto seja respeitado e acompanhado com apoio da equipe de cuidados paliativos tratando esta situação como um processo de luto antecipado, atendendo assim, às necessidades advindas da doença, bem como os conflitos psicológicos e sociais.

Além do sofrimento que já é esperado diante da perda, outro sentimento que pode ser prevenido e minimizado passa pelo controle da dor crônica, todavia as falas demonstram que este manejo ainda é subdimensionado e acarreta sofrimento tanto para os pacientes quando para os familiares/cuidadores, situação marcante no cotidiano dos participantes deste estudo, haja vista que a dor é subtratada como evidenciado nas falas.

Condição esta que é encontrada nos estudos como um descuidado resultante do subtratamento da dor crônica em consequência de uma prescrição medicamentosa inadequada no sentido de não atender a real necessidade do paciente, o que passa muitas vezes por não considerar o uso de um opioide potente como medicamento de escolha para o tratamento da dor crônica.

O tratamento farmacológico de acordo com a escada de três degraus que é a associação de analgésicos, AINES, opioides fracos e opioides fortes e coadjuvantes, preconizada pela Organização Mundial da Saúde (OMS) deve ser a base do controle da dor crônica, conforme sua mesuração ${ }^{16}$.

A analgesia é uma necessidade no contexto dos pacientes em cuidados paliativos, pois a dor é uma das sintomatologias mais desagradáveis que se possa vivenciar. Se não controlada, causa maiores complicações e aumenta o estresse ${ }^{17}$.

Assim é possível afirmar que o uso de analgésicos, especialmente dos opioides devem fazer parte dos cuidados prestados aos pacientes com uma doença terminal. Todavia, também se faz necessário que o familiar/cuidador seja orientado quanto ao uso desses medicamentos, pois em sua grande maioria as prescrições medicamentosas fazem parte da rotina desses pacientes e cuidadores, mas os mesmos desconhecem seus efeitos, suas ações e o seu uso sistemático e preventivo no controle da dor, muitas vezes isso faz com que eles sintam-se inseguros, como mostram os resultados deste estudo.

Por isso, é necessário que além da equipe de saúde, o paciente e o familiar devem ter conhecimento acerca da tolerabilidade e o tipo de dor, para que a prescrição seja realizada de modo adequado e entendida ${ }^{18}$.

Valendo destacar que além de todos os recursos medicamentosos, cuidar do paciente com dor crônica ultrapassa a administração de fármacos analgésicos e vai além, com a premente necessidade de uma relação profissional/familiar/paciente de modo empático, fortalecendo os vínculos afetivos com o propósito de aliviar, confortar, apoiar, promover o alívio do sofrimento tanto para o paciente quanto para seu familiar/cuidador ${ }^{16}$.

Assim, é importante reafirmar que uma das necessidades advindas da situação de ter uma doença terminal com consequente dor crônica, é o controle da dor. Esse controle deve ser realizado adequadamente e a partir de ações multiformes, agindo em todos os contextos álgicos, utilizando os analgésicos de acordo com a intensidade da dor, 
mas também, das intervenções não farmacológicas as quais devem fazer parte de um conjunto integrativo de todos os aspectos psicológico, social e espiritual. Vale ressaltar que as técnicas de alívio têm custos reduzidos que podem ser instruídos ao paciente e cuidador ${ }^{19}$.

Neste estudo, apenas um dos entrevistados cita o uso de um analgésico forte - a petidina (dolantina), mas nenhum cita o uso da morfina no tratamento da dor crônica. O recomendado pelo Ministério da Saúde é que para o tratamento das dores moderadas a intensa deve-se manter um controle rigoroso na administração de medicamentos, respeitando e mantendo intervalos fixos, pois assim assegura-se que a dose a ser administrada seja fornecida antes que o efeito da dose anterior tenha acabado, impedindo que os sintomas voltem a ser sentidos bem como impedindo a tolerância ao medicamento para que a dose seja mantida.

Deve ocorrer a orientação ao paciente e ao cuidador tanto escrita quanto verbal, sobre os nomes do medicamento, sua indicação, dosagem, intervalos e possíveis efeitos colaterais ${ }^{20}$.

Então, é possibilitado ao cuidador uma forma de melhor controle e manejo das prescrições e os possíveis efeitos colaterais que os medicamentos venham a causar, diminuindo o estresse do familiar/cuidador quanto ao uso de medicamentos, seus efeitos e reações.

A escolha do medicamento deve ser conforme a necessidade e o estado do paciente, conforme a OMS descreve na Escada Analgésica com recomendações quanto ao uso dos fármacos conforme a intensidade da dor, que vai do degrau da dor leve, moderada e severa ${ }^{21}$. Sempre lembrando que, quando os pacientes com dor crônica relatam a persistência da dor, isso indica que as estratégias de analgesia não estão atingindo o controle da dor ${ }^{22}$.

Tem-se a comunicação como uma ferramenta valiosa para a tomada de decisões nestes momentos, permitindo ao paciente a oportunidade de escolhas em relação ao tratamento, considerando suas opções e expectativas ${ }^{16,23}$. Sempre permitido que o familiar esteja junto ao paciente e equipe como parte de um elo comunicativo seguro no qual a verbalização das angústias e sentimentos são divididos por todos, proporcionado também o apoio emocional. Isso faz com que as terapêuticas estabelecidas tenham mais aceitação por parte do paciente e família.

As relações interpessoais utilizam a comunicação verbal e não verbal na emissão e recepção de mensagens, assim, a troca de informações por parte dos pacientes e familiares nas conversas é uma das evidências que tem um grau de grande valia. Assim as pessoas partilham significações e emoções próprias, tudo isso ocorre como uma troca de questionamentos e respostas geradas por essa partilha ${ }^{24}$. Notamos que essa troca, durante uma crise de dor, faz com que paciente e familiar tenham uma maior interação e cumplicidade e o suporte empático contribui para minimizar a crise de dor.

Um estudo realizado na cidade de Belo Horizonte (MG) com o objetivo de compreender o sofrimento do cuidador diante da situação-limite da terminalidade da existência, evidenciou que a conversa é um instrumento terapêutico que auxilia familiares e pacientes no percurso dos cuidados a pessoa com uma doença terminal ${ }^{25}$. Nela, as expectativas são expostas e o contato com o outro traz alívio durante as crises de dor, nos relatos deste estudo essa conversa durante a crise álgica é uma necessidade que o familiar tem para demonstrar ao seu ente querido que ele se importa com tudo que está acontecendo e que ele está ali fazendo o possível para aliviar todo sofrimento, tornando-se assim um instrumento terapêutico. 
Um dos objetivos dos cuidados paliativos é permitir a autonomia e a tomada de decisões do paciente no que diz respeito a sua saúde e nesse intuito a comunicação é uma ferramenta extremamente importante, não apenas entre cuidador e paciente, mas envolvendo também profissionais de saúde. Informações claras sobre prognósticos permitem que familiares e paciente vivenciem a terminalidade de forma menos dolorosa. Dessa maneira, a comunicação deve ser aperfeiçoada para diminuir o impacto emocional e permitir assimilação gradual da realidade $^{26}$.

Apesar de não ter aparecido nos resultados deste estudo, vale citar o uso das Práticas Integrativas e Complementares em Saúde (PICS) enquanto sistemas e recursos terapêuticos que visam estimular mecanismos naturais de alívio da dor por meio de tecnologias eficazes e seguras, com ênfase numa escuta acolhedora ${ }^{27}$. É preciso que essa medida de tratamento seja também reconhecida por cuidadores e equipe de saúde como auxílio no tratamento da dor crônica, pois, como já sinalizado, os familiares talvez utilizem as PICS, mas não as reconhecem como parte do tratamento ou como um instrumento terapêutico.

Há hoje o diálogo entre as práticas integrativas e a medicina convencional ${ }^{28-29}$. Portanto, há possibilidade de ensinar ao cuidador/familiar formas de utilizá-las de modo consciente na terapêutica do seu familiar.

Sendo assim, podemos destacar algumas das PICS que o familiar/cuidador pode utilizar como meio de tratamento no cuidado e prevenção de crises de dor como uso de plantas medicinais na forma de chá, práticas corporais e massagens ensinadas pela equipe de saúde previamente treinada para tal ${ }^{29}$.

\section{CONCLUSÃO}

Dentro de todo o contexto de sofrimento que engloba o cuidado de um ente querido em cuidados paliativos e com crises de dor crônica, o cuidador sofre ao ver seu familiar padecendo, o que revela a insuficiência do controle álgico empregado e infere uma fragilidade no preparo do familiar/cuidador para lidar com esta questão. A equipe de saúde precisa garantir que as orientações sejam apreendidas aos familiares num trabalho de educação em saúde a fim de evitar prolongamentos de sofrimento ao paciente e ao cuidador/familiar.

Como limitação do estudo, pode ser citada a dificuldade na identificação de participantes, considerando que as pessoas ainda demonstram seus próprios preconceitos em expor seus sofrimentos, assim tentam esconder que na família há uma pessoa doente e principalmente se esta foi diagnosticada com um câncer. Talvez tentando esconder da sociedade, para que não aponte seus sentimentos e fragilidades na luta diária frente uma doença terminal de um ente querido.

Espera-se que os resultados deste estudo possam sensibilizar os profissionais de saúde em prol de uma melhora no subtratamento da dor crônica e que os princípios filosóficos dos cuidados paliativos possam alcançar todos que deles necessitam e assim consigam ter uma vida digna e com o mínimo de sofrimento e aqueles em cuidados de fim de vida possam ter dignidade no processo de morrer e o seu sofrimento amenizado, assim como suas crises de dor controladas.

\section{CONFLITO DE INTERESSE}

As autoras afirmam não haver conflitos de interesses 


\section{REFERÊNCIAS}

1. Gomes ALZ, Othero MB. Cuidados Paliativo. Estud. av. Setembro/Dezembro 2016; 30(88). http://dx.doi.org/10.1590/s0103-40142016.30880011

2. Silva RS, Pereira A, Mussi FC. Comfort for a good death: perspective nursing staff's of intensive care. Esc. Anna Nery. Março 2015; 19(1): 40-46. http://www.scielo.br/pdf/ean/v19n1/en 1414-8145-ean-19-010040.pdf

3. Hermes HR, Lamarca ICA. Cuidados paliativos: uma abordagem a partir das categorias profissionais de saúde. Rev. Ciência \& Saúde Col. Setembro 2013. http://dx.doi.org/10.1590/S1413-81232013000900012

4. Andrade CG, Costa SFG, Lopes MEL. Cuidados paliativos: a comunicação como estratégia de cuidado para o paciente em fase terminal. Cienc. saúde coletiva. Setembro 2013; 18(9): 2523-2530. http://dx.doi.org/10.1590/S1413-81232013000900006

5. Inocenti A, Rodrigues IG, Miasso, AI. Vivencias e sentimentos do cuidador familiar do paciente oncológico em cuidados paliativos. Rev. Eletr. 2009; 11(4): 858-65.

https://www.fen.ufg.br/fen_revista/v11/n4/pdf/v11n4a11.pdf

6. Silva RS, Trindade GSS, Paixão GPN, Silva MJP. Conferência familiar em cuidados paliativos: análise de conceito. Rev Bras Enferm. 2017; 71(1): 218-26. http://www.scielo.br/pdf/reben/v71n1/pt 0034-7167-reben71-01-0206.pdf

7. Rocha AFP, Sposito AMP, Bortoli OS, Rodrigues FMS, Lima RAG, Nascimento LC. O Alívio da dor Oncológica: Estratégias Contadas por Adolescentes com Câncer. Texto Contexto Enferm. 2015; 24(1): 96104. http://dx.doi.org/10.1590/0104-07072015002120013

8. Vituno J. A Amostragem em Bola de Neve na pesquisa qualitativa: um debate em aberto. Temáticas. Ago/Dez. 2014; (22): 203-220. https://www.ifch.unicamp.br/ojs/index.php/tematicas/article/view/2144/1637

9. Bardin L. Análise de conteúdo. $3^{\text {a }}$ ed. Lisboa: Edições 70; 2011.

10. Brasil. Resolução n 466, de 12 de dezembro de 2012. Dispõe sobre as diretrizes e as normas regulamentadoras de pesquisa envolvendo seres humanos. Diário Oficial da União, Brasília, DF, 12 dezembro 2012. https://conselho.saude.gov.br/resolucoes/2012/Reso466.pdf

11. Brasil. Resolução $n^{\circ}$ 510, de 07 de abril de 2016. Dispõe sobre a Ética na Pesquisa na área de Ciências Humanas e Sociais. Diário Oficial da União, Brasília, DF, 07 de abril de 2016. http://conselho.saude.gov.br/resolucoes/2016/Reso510.pdf

12. Encarnação JF, Farinasso ALC. A família e o familiar cuidador de pacientes fora de possibilidades terapêuticas: uma revisão integrativa. Semina: Ciências Biológicas e da Saúde. Janeiro/Junho 2014; 35(1): 137-148. http://dx.doi.org/10.5433/1679-0367.2014v35n1p137 
13. Devik SA, Hellzen O, Enmarker I. Bereaved family members perspectives on suffering among older rural cancer patients in palliative home nursing care: A qualitative study. European Journal of Cancer Care. 2016; 26(6): 1-9. https://www.ncbi.nlm.nih.gov/pubmed/27859824

14. Radavalli EP, Demarchi EM, Vieira GC, Kohn R, Cyrino LAR. Pacientes em estado terminal: uma revisão de literatura. Arq Ciênc Saúde. Outubro/Dezembro 2011; 18(4): 162-5. http://www.repositorioracs.famerp.br/racs_ol/vol-18-4/IDZ\%204\%20-\%20out\%20dezembro\%202011.pdf

15. Areia NP, Major S, Relvas AP. Necessidades dos familiares de doentes terminais em cuidados paliativos: Revisão crítica da literatura. Psychologica. 2017; 60(1): 137-152.

http://impactumjournals.uc.pt/psychologica/article/view/4761

16. Oliveira AL, Sobrinho NP, Cunha BAS. Chronic cancer pain management by the nursing team. Rev. dor. 2016; 17(3): 219-222. http://www.dx.doi.org/10.5935/1806-0013.20160075

17. Instituto Nacional de Câncer. Cuidados paliativos oncológicos: controle da dor. Rio de Janeiro: INCA; 2001. . http://www1.inca.gov.br/publicacoes/manual_dor.pdf.

18.Krause LH. Aspectos Práticos da Prescrição de Analgésicos na Dor do Câncer. Revista do Hospital Universitário Pedro Ernesto, UERJ. 2012; Rio de Janeiro.

http://www.revista.hupe.uerj.br/detalhe artigo.asp?id=325

19. Feire MEM, Sawada NO, França ISX, Costa SFG, Oliveira CDB. Qualidade de vida relacionada à saúde de pacientes com câncer avançado: uma revisão integrativa. Rev Esc Enferm USP. 2014; 48(2):357-67. http://www.scielo.br/pdf/reeusp/v48n2/pt 0080-6234-reeusp-48-02-357.pdf.

20. Nogueira FL, Sakata RK. Sedação Paliativa do Paciente Terminal. Revista Brasileira de Anestesiologia. Julho-Agosto 2012; 62 (4): 580-592. http://www.scielo.br/pdf/rba/v62n4/v62n4a12.pdf.

21. Mendes TR, Boaventura RP, Castro MC, Mendonça MAO. Occurrence of pain in cancer patients in palliative care. Acta Paul Enferm. 2014; 27(4): 356-61. http://dx.doi.org/10.1590/1982-0194201400059

22. Oliveira Junior NJ, Oliveira SBS, Migowski ER, Riguel F. O papel da enfermagem no tratamento não farmacológico da dor de pacientes oncológicos. Rev. Dor. Setembro 2017; 18(3): 261-265. http://dx.doi.org/10.5935/1806-0013.20170112

23. Santos CKC, Andrade CG, Costa ICP, Lopes MEL, Silva CEG, Santos KFO. Comunicação em Cuidados Paliativos: Revisão Integrativa da Literatura. R Brás ci. 2014; 18(1):63-72.

http://www.periodicos.ufpb.br/ojs/index.php/rbcs/article/view/13312

24. Coelho MEM, Ferreira AC. Cuidados paliativos: narrativas do sofrimento na escuta do outro. Rev.Bioét. 2015; 23(2): 340-348. www.scielo.br/pdf/bioet/v23n2/1983-8034-bioet-23-2-0340.pdf

25. Sanchez KO, Ferreira NMLA, Dupas G, Costa DB. Apoio social à família do paciente com câncer: identificando caminhos e direções. Rev Bras Enferm. 2010; 63(2): 290-299.

http://www.scielo.br/pdf/reben/v63n2/19.pdf 
26. Machado JC, Reis HFT, Sena ELS, Silva RSS, Boery RNSO, Vilela ABA. El fenomeno de la conspiración del silencio en pacientes en cuidados paliativos: una revisión integrativa. Revista Enfermería Actual. 2019; (36): 1-12. https://revistas.ucr.ac.cr/index.php/enfermeria/article/view/34235/36291

27. Andrade KYA, Silveira YMA, Salvador TCO, Nascimento PA, Tourinho CPV, Santos FS, Pereira EV. Práticas integrativas e complementares no tratamento oncológico e o papel da enfermagem. Revista de Pesquisa Cuidado é Fundamental Online. 2015; 7(4): 3163- 3174. http://www.scielo.br/scielo.php?pid=S1413-81232013000900006\&script $=$ sci abstract

28. Telesi Junior E. Práticas integrativas e complementares em saúde, uma nova eficácia para o SUS. Estud.av; 2016; 30(86): 99-112. http://dx.doi.org/10.1590/S0103-40142016.00100007

29. Sousa IMC, Tesser CD. Medicina Tradicional e Complementar no Brasil: inserção no Sistema Único de Saúde e integração com a atenção primária. Cad. Saúde Pública. 2017; 33(1):e00150215.

https://doi.org/10.1590/0102-311X00150215 